\title{
Development of a prostacyclin-agonist-eluting aortic stent graft enhancing biological attachment to the aortic wall
}

\author{
Yoshiki Watanabe, MD, ${ }^{a}$ Shigeru Miyagawa, MD, PhD, ${ }^{\text {a }}$ Satsuki Fukushima, MD, PhD, ${ }^{\mathrm{a}}$ \\ Takashi Daimon, $\mathrm{PhD},{ }^{\mathrm{b}}$ Yukitoshi Shirakawa, MD, PhD, ${ }^{\mathrm{a}}$ Toru Kuratani, MD, $\mathrm{PhD},{ }^{\mathrm{a}}$ and \\ Yoshiki Sawa, MD, $\mathrm{PhD}^{\mathrm{a}}$
}

\begin{abstract}
Objectives: Stent graft-related complications, including endoleaks and graft migration, are partly attributed to insufficient graft attachment to the aortic wall. ONO-1301, a stable synthetic prostacyclin agonist, reportedly reorganizes extracellular matrices, enhancing tissue healing. We hypothesized that ONO-1301-eluting stent grafts may strengthen graft attachment to the aortic wall.
\end{abstract}

Methods: Polylactic acid polymer-conjugated ONO-1301, which releases ONO-1301 into adjacent tissues over 3 months $(\mathrm{ONO}(+)$ group $)$, or polylactic acid polymer only $(\mathrm{ONO}(-)$ group) was coated onto the stent graft and placed in the descending thoracic aorta of canines weighing 16 to $20 \mathrm{~kg}$ under fluoroscopic guidance. Examinations occurred at 1,2 , or 3 months postoperatively ( $\mathrm{n}=6$ for each time point and group).

Results: ONO-1301 aortic-wall concentrations were within the effective range even at 3 months. The maximal load for tearing the graft from the aortic wall ex vivo was significantly greater in the $\mathrm{ONO}(+)$ group than in the $\mathrm{ONO}(-)$ group $(117.1 \% \pm 44.4 \%, 133.9 \% \pm 23.2 \%$, and $119.9 \% \pm 13.5 \%$ at 1,2 , and 3 months, respectively; $P=.0007)$. Immunohistochemical examination revealed abundant $\alpha$-smooth muscle actin-positive cells in the neointima in both groups. The fibrotic area between the graft and the aortic wall was significantly larger $(P<.0001)$, and migrating cells into the graft fabric were significantly greater $(P=.0003)$ in the $\mathrm{ONO}(+)$ group than in the $\mathrm{ONO}(-)$ group.

Conclusions: In canines, the ONO-1301-eluting stent graft enhanced tissue reorganization and improved the attachment between the graft and the aortic wall. This new device may be useful in preventing inadequate graft attachment to the aortic wall. (J Thorac Cardiovasc Surg 2014;148:2325-34)

Supplemental material is available online.

Stent graft implantation via the endovascular approach has been regarded as the standard treatment for atherosclerotic aortic aneurysms in the last decade, ${ }^{1-3}$ although stent graftrelated complications such as stent migration, kinking, and endoleaks have not been fully resolved. Malina and colleagues $^{4}$ suggested that the attachment between the

\footnotetext{
From the Department of Cardiovascular Surgery, ${ }^{\mathrm{a}}$ Osaka University Graduate School of Medicine, Osaka, Japan; and Department of Biostatistics, ${ }^{b}$ Hyogo College of Medicine, Hyogo, Japan.

This work was financially supported by the Japan Society for the Promotion of Science Core-to-Core Program (grant no. 21003) and the New Energy Industrial Technology Development Organization, Japan (grant no. P10004).

Disclosures: ONO-1301 encapsulated in PLA microspheres was provided by Ono Pharmaceutical Company. Authors have nothing to disclose with regard to commercial support.

Received for publication Jan 31, 2014; revisions received March 29, 2014; accepted for publication April 11, 2014; available ahead of print Sept 12, 2014.

Address for reprints: Yoshiki Sawa, MD, PhD, Department of Cardiovascular Surgery, Osaka University Graduate School of Medicine, 2-2 Yamadaoka, Suita, Osaka 565-0871, Japan (E-mail: sawa-p@surg1.med.osaka-u.ac.jp). $0022-5223 / \$ 36.00$

Copyright (c) 2014 by The American Association for Thoracic Surgery http://dx.doi.org/10.1016/j.jtcvs.2014.04.024
}

implanted stent graft and the native aortic wall was histologically poor, contributing to stent graft-related complications. It is theorized that adequate graft attachment to the aorta would be accomplished by native cell migration producing fibrotic tissues into the graft materials and neointimal formation over the graft surface.

ONO- $1301^{5-8}$ is a chemically and biologically stable synthetic prostacyclin agonist producing long-lasting prostacyclin activity when administered in vivo. ONO1301 carries regenerative effects that enhance the native biological healing process, such as reorganization of fibrous tissue or vascular structures, by inducing vascular endothelial growth factor (VEGF) or stromal cell-derived factor (SDF)-1 expression in vascular smooth muscle cells and fibroblasts. ${ }^{9-11}$ ONO-1301 can be conjugated with polylactic acid (PLA) polymer to form ONO-1301 microspheres (ONO-1301MS) that release ONO-1301 into adjacent tissues for 3 to 4 months. We hypothesized that the presence of ONO-1301MS in the stent graft may strengthen the implanted stent graft attachment to the aortic wall. Therefore, in the present study, we developed an ONO-1301-eluting stent graft, which was inserted into the thoracic descending aorta in a normal canine model, to explore the feasibility, safety, and efficacy of this drug-eluting stent graft for treating aortic pathologies. 


$$
\begin{aligned}
& \text { Abbreviations and Acronyms } \\
& \begin{aligned}
\text { COX } & =\text { cyclooxygenase } \\
\text { HE } & =\text { hematoxylin-eosin } \\
\text { PLA } & =\text { polylactic acid } \\
\text { SDF } & =\text { stromal cell-derived factor } \\
\text { SMA } & =\text { smooth muscle actin } \\
\text { VEGF } & =\text { vascular endothelial growth factor }
\end{aligned}
\end{aligned}
$$

\section{METHODS}

The Osaka University Graduate School of Medicine ethics committee approved the studies. All animals were treated in compliance with the "Guide for the Care and Use of Laboratory Animals" (National Institutes of Health publication). Human cells were treated in compliance with the Declaration of Helsinki.

\section{Long-Release ONO-1301 Microsphere}

ONO-1301 was conjugated with PLA polymers, rather than polylactic and glycolic acid, as previously reported ${ }^{12}$ at ONO Pharmaceutical Company (Osaka, Japan). The drug-releasing capacity was estimated in advance of this study, and these microspheres were proven to have a longer release time (3-4 months) than polylactic and glycolic acid-synthesized microspheres (Figure 1, A).$^{8-11}$ ONO Pharmaceutical Company provided the microspheres with or without ONO-1301.

\section{Preparation of ONO-1301-Eluting Stent Graft}

A stainless-steel stent (Gianturco Z stent, $30 \mathrm{~mm}$; Cook, Bloomington, Ind) was sutured inside a Dacron woven graft (J Graft Woven-Graft, WST series 14-18 mm; UBE Junken Medical, Tokyo, Japan) to create a 25-mm-long handmade stent graft (Figure 1,B). Subsequently, $5 \mathrm{mg} / \mathrm{kg}$ of ONO-1301MS or PLA microspheres only was suspended in $10 \%$ dissolved gelatin (HMG-BP; Nippi, Tokyo, Japan); this mixture was applied to the outer surface of the stent graft and dried to create the stent graft with $(\mathrm{ONO}(+)$ group) or without $(\mathrm{ONO}(-)$ group $)$ the ONO-1301 elution.

\section{Fluoroscopy-Guided Endovascular Implantation of the Stent Graft into a Canine Model}

Mongrel dogs (16-20 kg; Oriental Yeast, Tokyo, Japan) underwent general anesthesia by submucosal injection of $20 \mathrm{mg} / \mathrm{kg}$ ketamine (Sankyo, Tokyo, Japan) and $2 \mathrm{mg} / \mathrm{kg}$ xylazine (Bayer Medical, Tokyo, Japan), followed by intravenous infusion of $10 \mathrm{mg} / \mathrm{kg} / \mathrm{h}$ propofol (AstraZeneca, London, UK) and inhalation of $1.5 \%$ sevoflurane. First, the thoracic descending aortic diameter was measured by computed tomography angiography; then, on the basis of recommendations in previous reports, we created a handmade stent graft that was $10 \%$ to $20 \%$ larger than the measured diameter. ${ }^{12,13}$

Subsequently, in the right lateral position, an $18 \mathrm{~F}$ DrySeal sheath (WL Gore \& Associates, Inc, Flagstaff, Ariz) containing the stent graft was introduced into the abdominal aorta via a retroperitoneal approach under fluoroscopic guidance (Figure 1,C); then, the stent graft was deployed into the thoracic descending aorta, followed by balloon touch-up using a $20 \times 40 \mathrm{~mm}$ MAXILD (Cordis; Johnson \& Johnson, Miami, Fla) (Figure 1,D). The animals were humanely killed at 1, 2, or 3 months after the procedure under general anesthesia with an overdose of intravenous sodium pentobarbital $(18 \mathrm{mg} / \mathrm{kg})$ to achieve complete sedation followed by administration of potassium-based solution intravenously to ensure that they were dead $(n=6$ for each time point and group).

\section{Handling of Specimens}

The explanted aorta, including the stent grafts, was opened longitudinally and photographed, and the stent materials were removed from the graft for further assessment (Figure 1,E). Immediately after the biomechanical test, the aortic wall tissue that dissociated from the graft fabric was frozen to analyze the ONO-1301 concentration. Neointimal tissues were separated from the graft and stored in RNAlater (Ambion, Austin, Tex) at $-20^{\circ} \mathrm{C}$.

\section{ONO-1301 Concentrations in the Aortic Wall and Blood Plasma}

ONO-1301 concentrations in the aortic wall at 1,2, and 3 months after stent graft implantation were determined using liquid chromatographytandem mass spectrometry ( $\mathrm{n}=4$ at each time point). Blood samples were obtained at 5 minutes, 3 hours, 1 week, 2 weeks, 1 month, 2 months, and 3 months after stent graft implantation. ONO-1301 levels in the plasma were measured by liquid chromatography-tandem mass spectrometry ( $\mathrm{n}=4$ at each time point). ${ }^{14}$

\section{Biomechanical Assessment}

We performed biomechanical assessments using Tensilon RTC-1150A (Orientec, Tokyo, Japan) on specimen sections measuring $5 \times 10 \mathrm{~mm}$. The woven graft was pulled from the aortic wall by connecting it to the metallic cylinder of the machine, which produced a constant tension $(50 \mathrm{~mm} / \mathrm{min})$, until the graft detached from the aorta. The associated computer software recorded a load-deformation plot to measure the maximum load (Newton $[\mathrm{N}]$ ) required for graft displacement. Seven specimens were tested from each sample ( $\mathrm{n}=6$ at each time point) to obtain the average value, after excluding the minimum and maximum values.

\section{Histologic Assessment}

The paraffin-embedded specimens were sliced at $0.5 \mu \mathrm{m}$ and stained with hematoxylin-eosin (HE) or Masson's trichrome. The sections were labeled with anti-CD31 antibody (Dako, Glostrup, Denmark) or anti- $\alpha$-smooth muscle actin ( $\alpha$ SMA) antibody (Dako) and visualized by the labeled streptavidin biotin staining method (Dako). The sections were labeled with primary antibodies against CD31 (Dako), $\alpha$ SMA (Abcam, Cambridge, UK), fibroblast specific antigen-1 (Abcam), or IP receptor (Abcam) and visualized by fluorescence-conjugated secondary antibodies (Life Technologies, Grand Island, NY), with counterstaining by Hoechst 33342 solution (Dojindo, Kumamoto, Japan). The extent of the fibrotic area in the Masson's trichrome-stained sections was quantified using Biorevo BZ-9000 (Keyence, Osaka, Japan) that calculated the ratio of the fibrotic area to the total tissue area to provide an indication of the fibrous tissue accumulation in the gap between the graft and the aortic wall. In each sample, 6 fields were estimated and averaged ( $n=6$ at each time point). The number of cells migrating into the graft fabric was counted on HE-stained sections. The number of nuclei per unit area was estimated in 10 fields in each sample ( $n=6$ at each time point).

\section{Quantitative Real-Time Polymerase Chain Reaction}

Total RNA was extracted from the neointima using the RNeasy Kit and reverse transcribed using Omniscript Reverse transcriptase (Qiagen, Hilden, Germany). Real-time polymerase chain reaction was performed with ABI PRISM 7700 (Applied Biosystems, Foster City, Calif) using the primers for VEGF (cf02623449-m1), SDF-1 (cf02625258-m1), and beta-2-microglobulin (cf2659077-m1) (Applied Biosystems). The average copy number of gene transcripts for VEGF or SDF-1 was normalized to the beta-2-microglobulin gene.

\section{In Vitro Study}

Aortic smooth muscle cells, aortic fibroblasts, or aortic endothelial cells of human origin (Lonza, Basel, Switzerland) were cultured in serum-free 

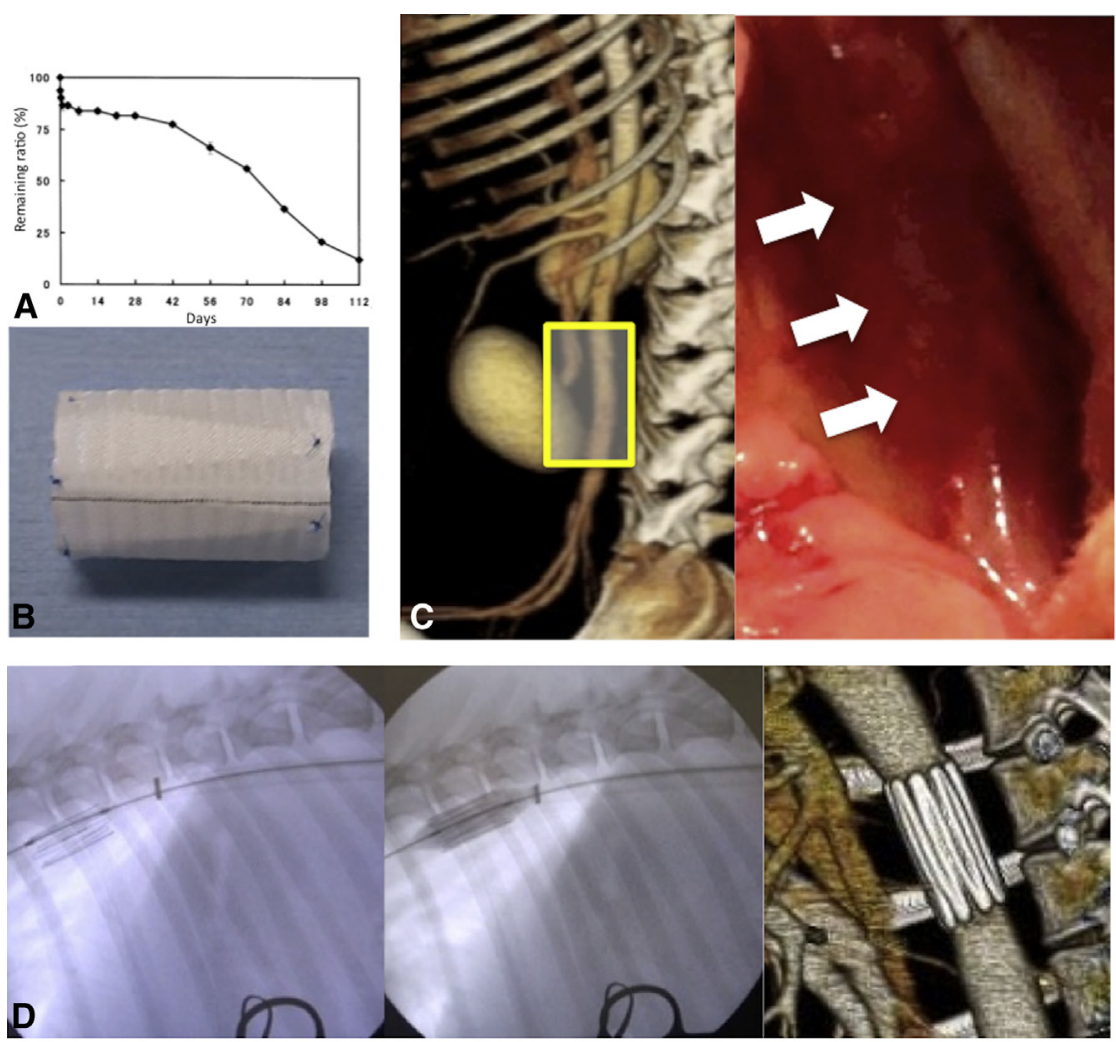

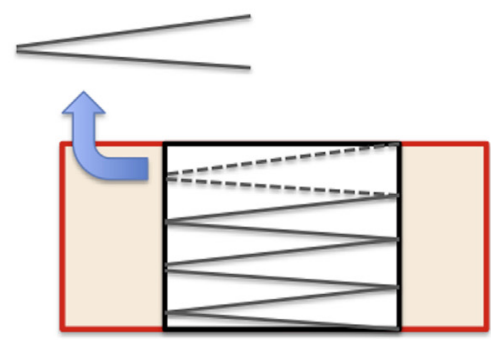

E

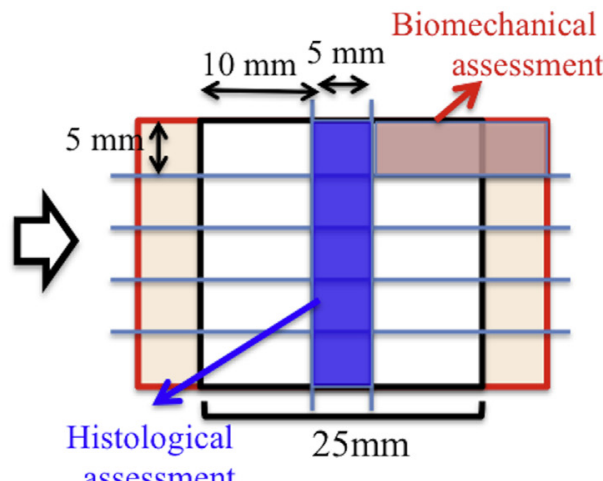

assessment

FIGURE 1. A, ONO-1301 release curve of ONO-1301 microspheres synthesized with PLA polymers. The drug-eluting capacity was sustained even at 3 months after the initiation of degradation. B. The stent grafts were handmade and composed of stainless-steel $\mathrm{Z}$ stent and woven polyester graft. $\mathrm{C}$, The canine abdominal aorta was exposed via the retroperitoneal approach. D, The stent graft was introduced into the thoracic aorta under fluoroscopic guidance, followed by post-balloon dilatation. E, Stent materials were removed from the extracted specimen and sectioned for assessments.

medium for 24 hours and then incubated with $0 \mathrm{nM}, 10 \mathrm{nM}, 100 \mathrm{nM}$, and $1000 \mathrm{nM}$ of ONO-1301 ( $\mathrm{n}=3 \mathrm{each}$ ). Supernatant was collected after 72 hours ( 24 hours in endothelial cells because of their tendency to degrade in the serum-free medium), and VEGF and SDF-1 levels were measured using an enzyme-linked immunosorbent assay kit (R\&D Systems Inc, Minneapolis, Minn).

\section{Statistical Analysis}

Continuous variables are summarized as mean \pm standard deviation. Concentrations of ONO-1301 in the aortic wall were compared using 1 -way analyses of variance, followed by post hoc pairwise independent $t$ tests. Exposed stent length and biomechanical and histologic assessment data were analyzed using 2-way analyses of variance with each group and month as the main effects and the first-order interaction effect between each parameter, followed by post hoc pairwise independent $t$ tests. In vitro data were analyzed through pairwise comparisons between the control $(0 \mathrm{nM})$ and the other levels of ONO-1301 (10, 100, and $1000 \mathrm{nM})$. The multiplicity in pairwise comparisons was corrected using the Bonferroni method. All probability values are 2-sided. Statistical analysis was performed with JMP software (SAS Institute Inc, Cary, NC).

\section{RESULTS}

Procedure-Related Mortality and Morbidity

Thirty-six animals completed the study, and 2 animals failed to complete; 1 died of cardiac arrhythmia 


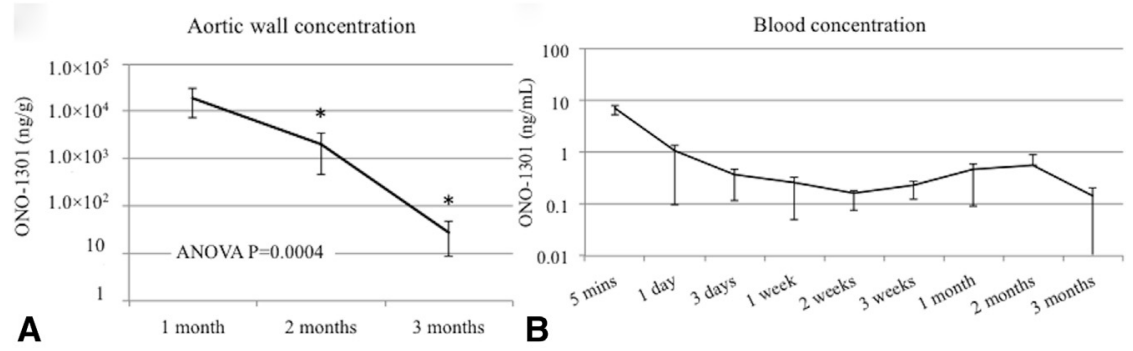

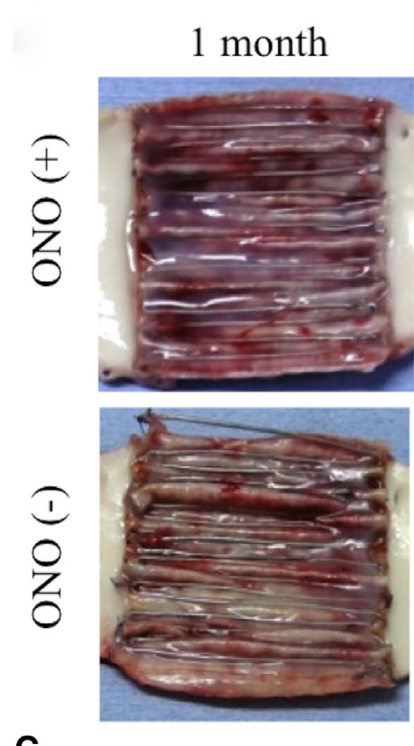

C

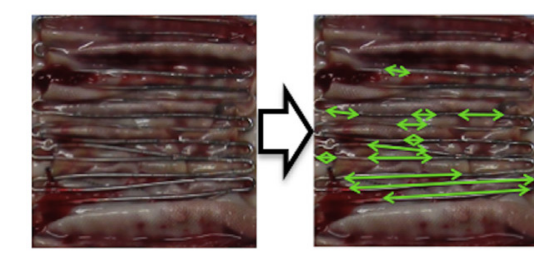

D
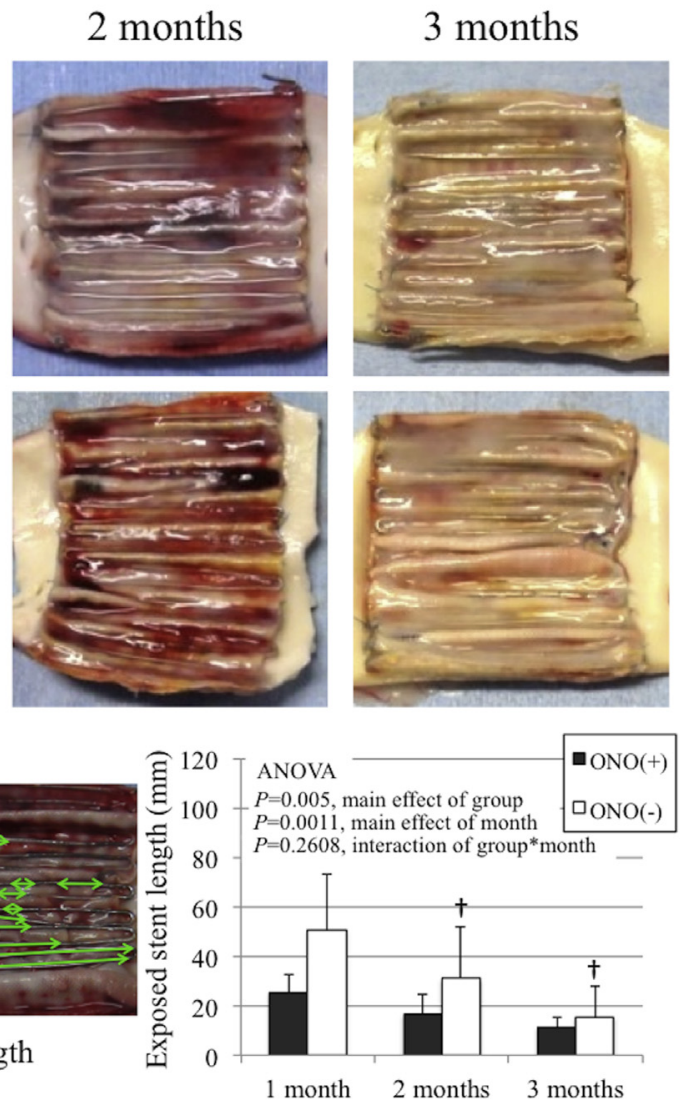

FIGURE 2. A, ONO-1301 concentration in the aortic wall in the $\mathrm{ONO}(+)$ group. Although the drug concentration at the graft attachment site decreased over time, it remained in the effective range over 3 months ( ${ }^{*} P<.05$ vs 1 month). B, Plasma ONO-1301 levels in the ONO-1301(+) group. The drug concentration remained below the safety level. C, Macroscopic view of the inner lumen. Neointimal formation and thrombus degradation progressed, and this process was observed earlier in the $\mathrm{ONO}(+)$ group. D, The exposed stent length decreased over time and was shorter in the $\mathrm{ONO}(+)$ group $(\dagger P<.05$ vs 1 month of the corresponding group). ANOVA, Analysis of variance.

immediately after sheath removal, and the other was euthanized because of persistent paraplegia. Transient hemiparaplegia was observed in 3 animals after the procedure; however, they completely improved with supplemented glucose solution infusion. Neither an embolic event nor stent graft migration occurred in any animal.

\section{Stable ONO-1301 Concentrations in the Aortic Wall and Blood Plasma}

Although the ONO-1301 concentrations in the aortic wall tissue under the stent graft attachment site decreased gradually until 3 months after the implantation, they remained within the effective range at 3 months
(Figure 2, A). The blood plasma ONO-1301 concentrations were the highest at 5 minutes after the ONO-1301-eluting stent graft implantation; they gradually decreased over 2 weeks, slightly increased at 1 month, and decreased at 3 months after the procedure (Figure 2, B). ONO-1301 was not detected in any samples, including aortic wall tissue or blood plasma, from the $\mathrm{ONO}(-)$ group.

\section{Enhanced Adventitial Neovascularization and Neointimal Formation by ONO-1301 Elution}

The adventitial appearance and neointimal formation in the aorta were assessed after the stent graft implantation in the $\mathrm{ONO}(+)$ group and compared with that in the $\mathrm{ONO}(-)$ 

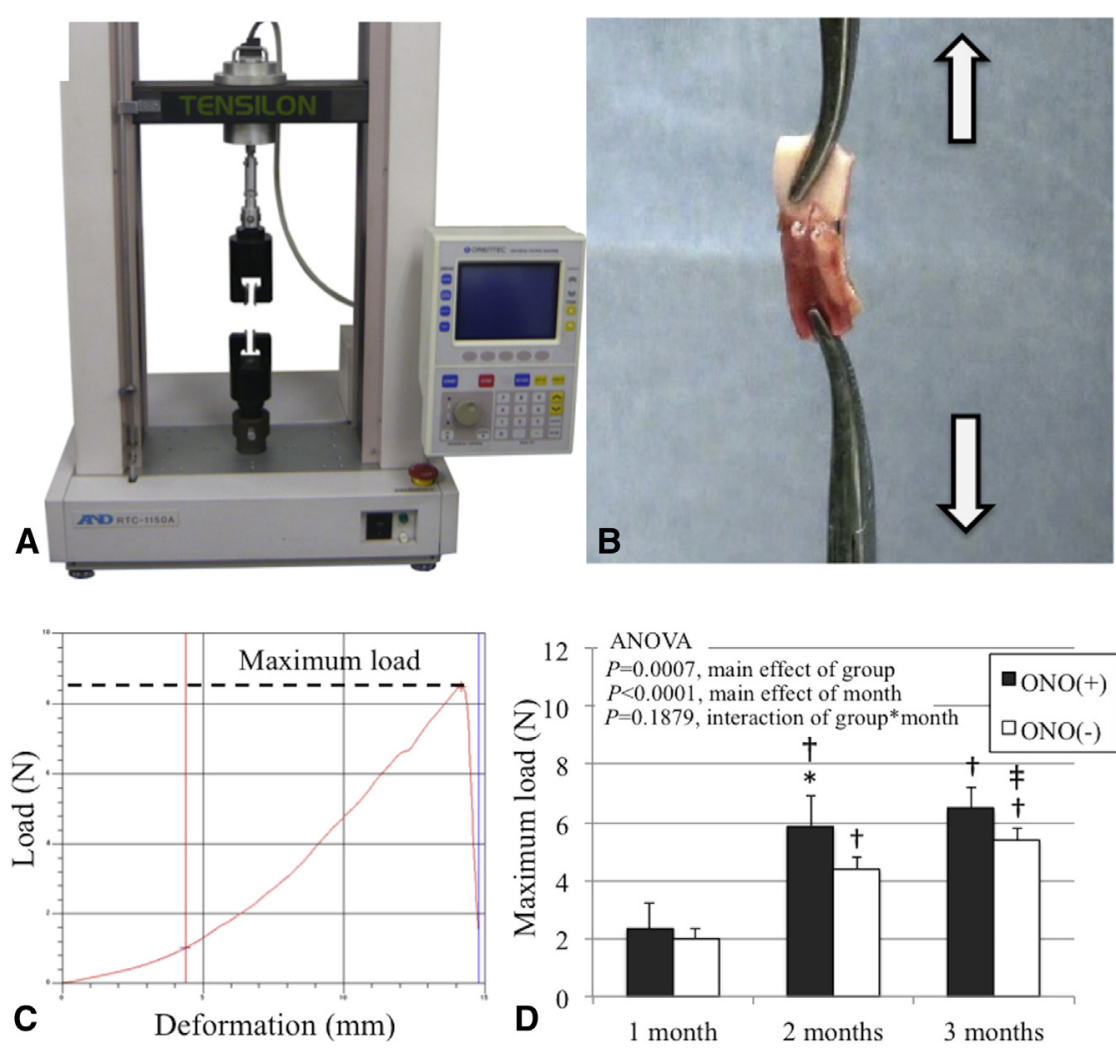

FIGURE 3. A, Tensilon RTC-1150A (Orientec, Tokyo, Japan). B, Tension was applied to the specimen placed into the metallic cylinder of the machine using mosquito clamps. C, The maximal load required to displace the graft from the aortic wall was evaluated by the load-deformation plot. D, The maximum load needed to displace the graft fabric from the aortic wall increased over time and was greater in the ONO-1301( + ) group than in the $\mathrm{ONO}(-)$ group, especially 2 months after surgery ( $* P<.05$ vs $\mathrm{ONO}(-)$ group, $\dagger P<.05$ vs 1 month of the corresponding group, $\ddagger P<.05$ vs 2 months of the corresponding group). ANOVA, Analysis of variance.

group. At 2 months after stent graft implantation, the adventitia of the aorta showed rich vasculature corresponding to the stent graft implantation site compared with the area remote from the stent graft in both groups; further, this vasculature appeared to be increased in the $\mathrm{ONO}(+)$ group compared with that in the $\mathrm{ONO}(-)$ group (Figure E1, $A$ and $B$ ). In the inner lumen of the stent graft implantation site, progression of neointimal formation and a decrease of red thrombus under the neointima were observed in both groups in a timedependent manner; however, these changes occurred earlier in the $\mathrm{ONO}(+)$ group than in the $\mathrm{ONO}(-)$ group (Figure 2, $C)$. The length of the exposed stent in the inner lumen, which indicates poor neointimal formation, significantly decreased over time $(P=.0011)$ and was greater in the $\mathrm{ONO}(-)$ group than in the $\mathrm{ONO}(+)$ group $(P=.0050)(201.1 \% \pm 89.8 \%$, $187.1 \% \pm 127.6 \%$, and $134.5 \% \pm 109.8 \%$ at 1,2 , and 3 months, respectively) (Figure 2, D). Hemodynamic stenosis of the inner lumen by excessive neointimal formation was absent in all of the samples.

\section{Enhanced Mechanical Force Required to Detach the Graft From the Aorta by ONO-1301}

The maximum detachment load gradually increased in both groups over the 3 months $(P<.0001)$. Moreover, maximum load required at 2 months was substantially greater than at 1 month in both groups and then did not differ from that at 3 months in both groups $(250.1 \%$ $\pm 43.3 \%$ [ 2 months vs 1 month] and $110.2 \% \pm 12.4 \%$ [3 months vs 2 months] in the $\mathrm{ONO}(+)$ group; $218.6 \% \pm$ $20.4 \%$ [2 months vs 1 month] and $123.1 \% \pm 9.0 \%$ [3 months vs 2 months] in the $\mathrm{ONO}(-)$ group), suggesting that the tissue healing process was almost accomplished at approximately 3 months. On the other hand, the maximum load required in the $\mathrm{ONO}(+)$ group was significantly greater than that in the $\mathrm{ONO}(-)$ group $(P=.0007)$, especially at 2 months $(P=.0492)(117.1 \% \pm 44.4 \%$, $133.9 \% \pm 23.2 \%$, and $119.9 \% \pm 13.5 \%$ at 1,2 , and 3 months, respectively) (Figure 3).

\section{Histologic Evidence of Enhanced Neointimal Formation by ONO-1301 Elution}

In HE-stained sections, the inner graft surface was covered by denser neointima to produce a smooth surface in the $\mathrm{ONO}(+)$ group than in the $\mathrm{ONO}(-)$ group at 2 months (Figure 4, $A-C$ ). In addition, the neointima contained richer CD31-positive capillary networks in the $\mathrm{ONO}(+)$ group than in the $\mathrm{ONO}(-)$ group at 2 months (Figure E1, $B$ and $C)$. Moreover, the neointima contained rich $\alpha$ SMA-positive cell components with fibrous components in the $\mathrm{ONO}(+)$ 

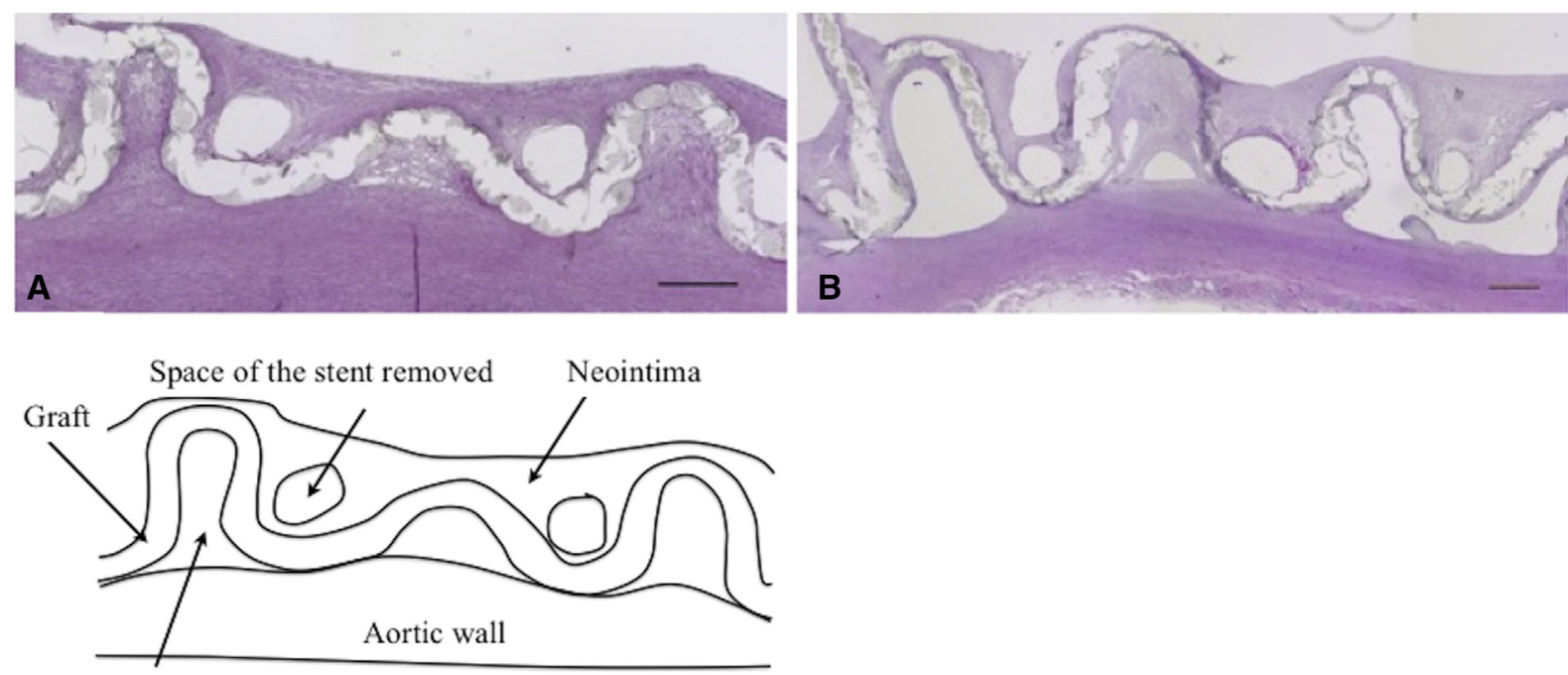

C

Gap between the aortic wall and the graft fabric
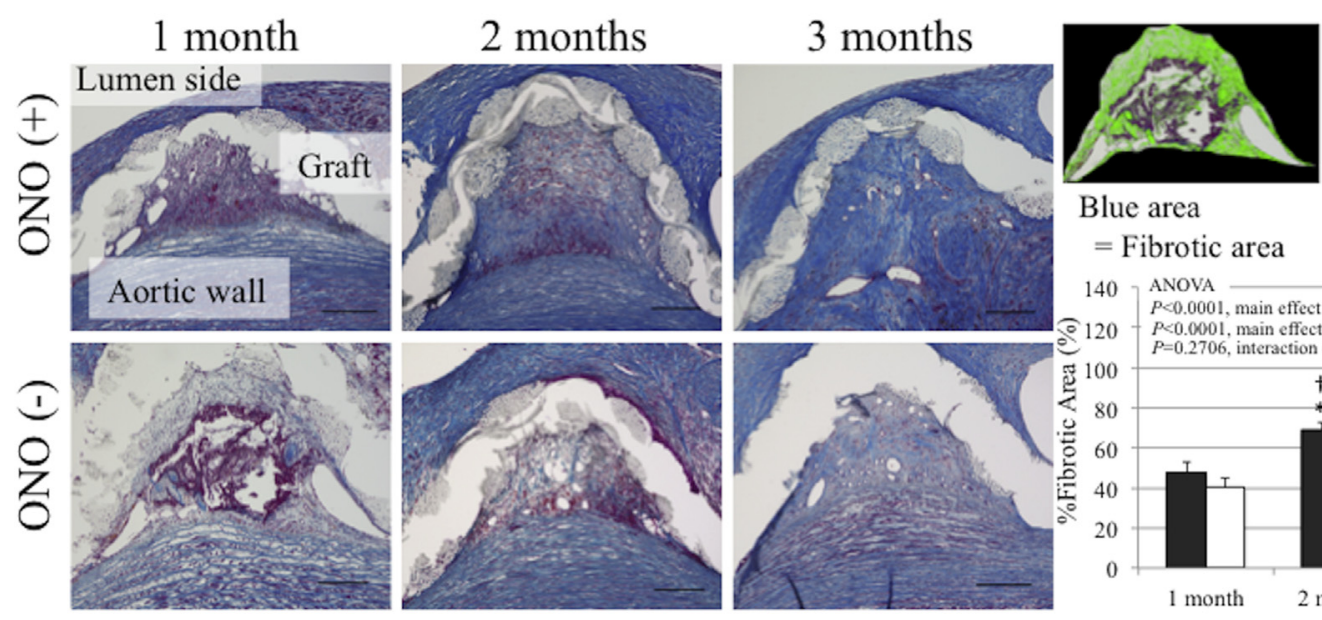

Blue area
$=$ Fibrotic area

Color Area

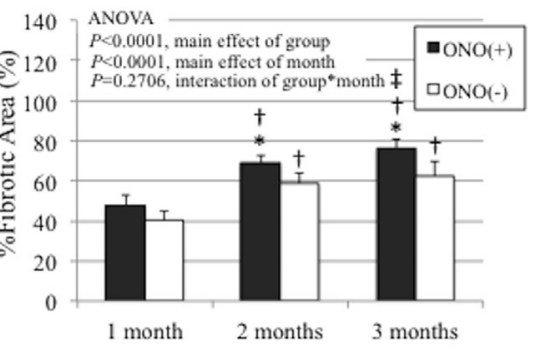

D
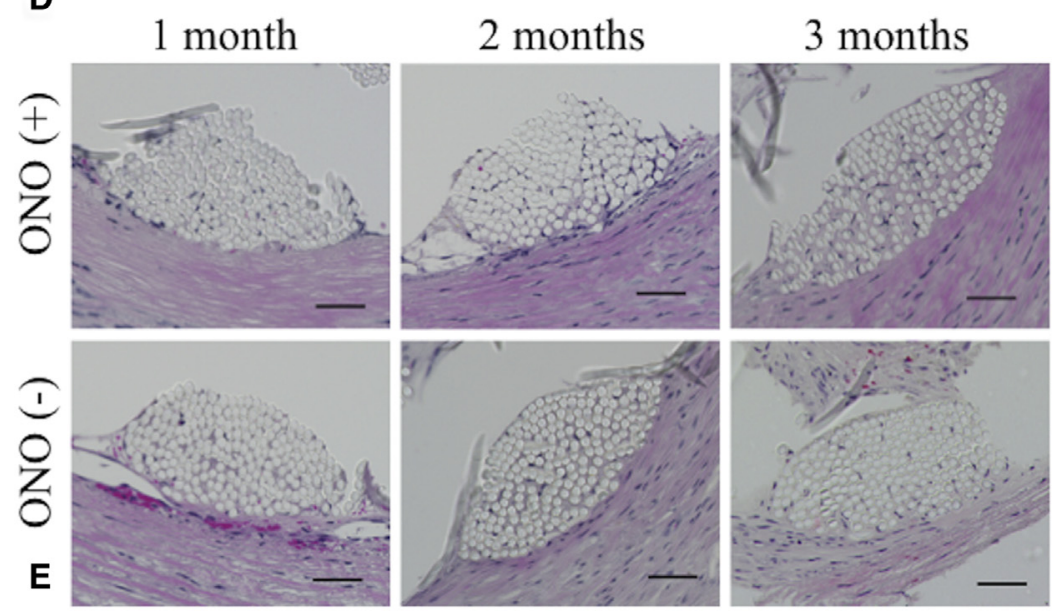

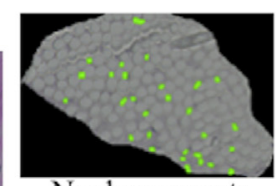

Nucleus counts ${ }_{\left(10^{-3}\right)}=$ Cell numbers

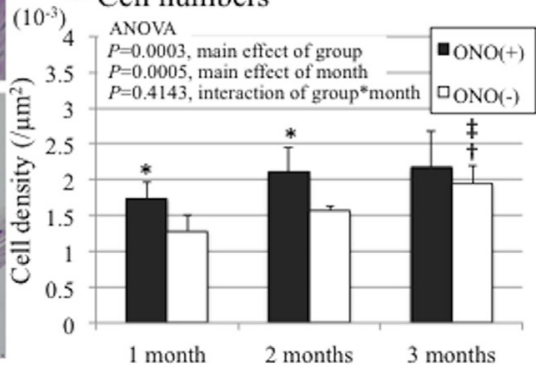

FIGURE 4. A-C, Neointimal tissue was observed on the graft fabric; new tissue also was seen between the aortic wall and the graft fabric (HE staining: $\mathrm{A}, \mathrm{ONO}(+)$; B, ONO(-) at 2 months; C, The scheme). D, Fibrotic area was assessed using Masson's trichrome staining. The \% fibrotic area increased in a time-dependent manner and was greater in the ONO treatment group, especially at 2 and 3 months ( $\%$ fibrotic area [\%] $=[$ fibrotic area]/[total tissue area]). Scale bar $=200 \mu \mathrm{m}$. E, Migrating cells into the graft fabric were assessed by HE staining. The cell density was greater in the ONO $(+)$ group at both 1 and 2 months after the procedure (cell density $=$ [cell counts]/[area of graft fabric] $)$. Scale bar $=50 \mu \mathrm{m}(* P<.05 \mathrm{vs} \mathrm{ONO}(-)$ group, $\dagger P<.05 \mathrm{vs} 1 \mathrm{month}$ of the corresponding group, $\ddagger P<.05$ vs 2 months of the corresponding group). ANOVA, Analysis of variance. 


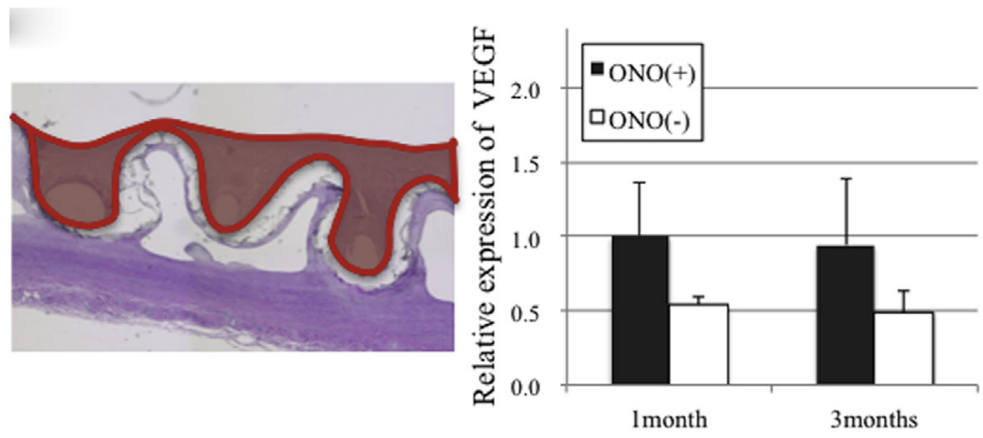

A
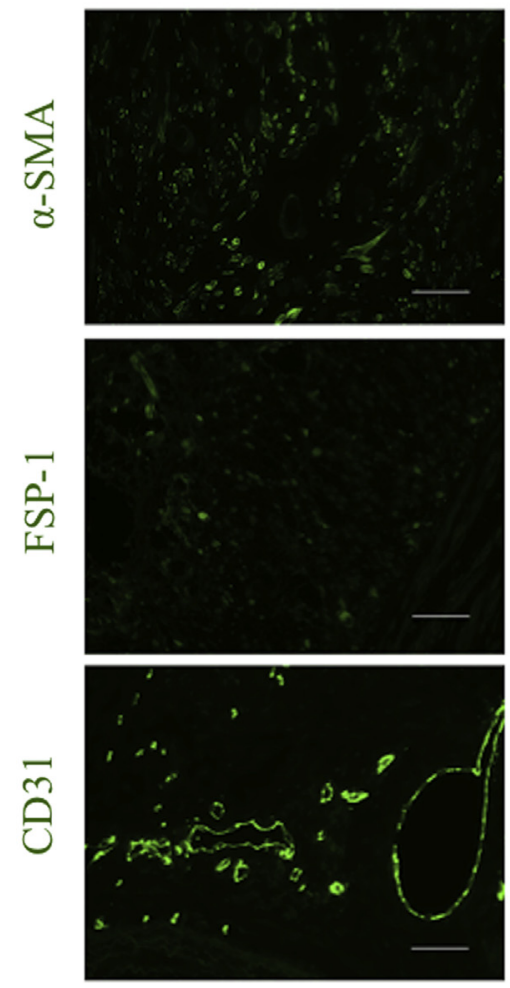

$\mathbf{B}$

Smooth muscle cells

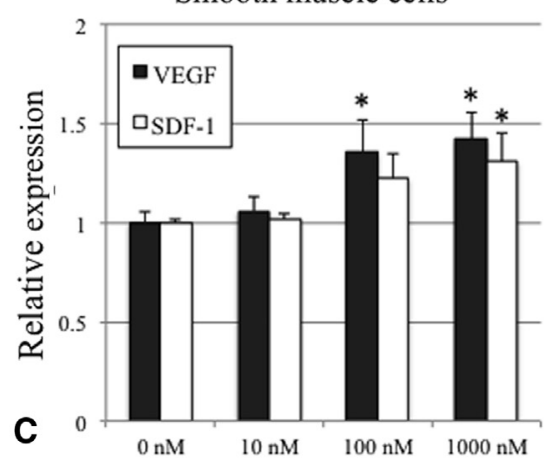

IP receptor

Fibroblasts
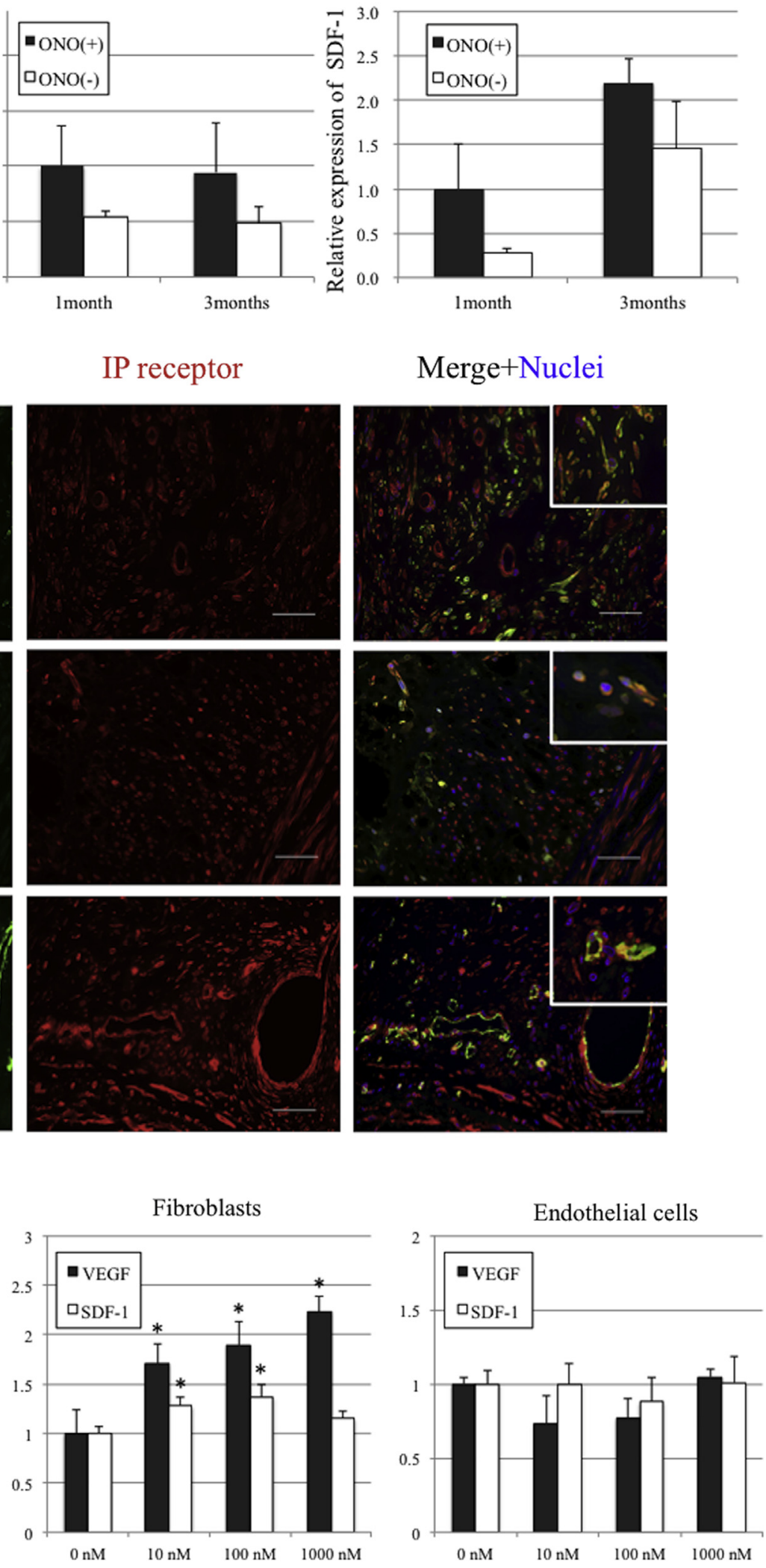

FIGURE 5. A, Messenger RNA expressions of VEGF and SDF-1 were analyzed in the neointimal tissue (ie, area stained red). The expressions of VEGF and SDF-1 tended to be upregulated at 1 month and 3 months. B, Immunohistochemically, the IP receptor in the aortic wall was coexpressed with CD31positive, $\alpha$ SMA-positive, and fibroblast-specific antigen-1-positive cells. Scale bar $=50 \mu \mathrm{m}$. C, The expressions of VEGF and SDF-1 were upregulated when ONO-1301 was added to the culture medium of aortic smooth muscle cells and aortic fibroblasts $(* P<.05$ vs 0 nM). FSP, Fibroblast specific antigen; $S D F$, stromal cell-derived factor; $S M A$, smooth muscle actin; $V E G F$, vascular endothelial growth factor; $I P$, prostacyclin; $C D$, cluster of differentiation. 
group compared with the $\mathrm{ONO}(-)$ group, wherein sparse fibrous components predominated with a small number of $\alpha$ SMA-positive cells (Figure E1, $D$ and $E$ ).

\section{Histologic Evidence of Enhanced Tissue Accumulation Under the Graft by ONO-1301}

Fibrous tissue components gradually predominated in the gap between the graft and the aortic wall with decreased red thrombus in a time-dependent manner in both groups $(P<.0001)$. These fibrotic areas were significantly larger in the $\mathrm{ONO}(+)$ group than in the $\mathrm{ONO}(-)$ group $(P<.0001)$, especially at 2 and 3 months after stent graft implantation $(P=.0110$ and $P=.0129$, respectively) $(117.1 \% \pm$ $13.9 \%, 117.2 \% \pm 7.1 \%$, and $122.8 \% \pm 6.2 \%$ at 1,2 , and 3 months, respectively) (Figure 4,D). Moreover, the number of cells present inside the graft fabric significantly increased over time $(P=.0005)$, and a greater number of cells were present in the $\mathrm{ONO}(+)$ group than in the $\mathrm{ONO}(-)$ group $(P=.0003)$, especially at 1 and 2 months after graft implantation $(P=.0162$ and $P=.0111$, respectively $)$ $(135.9 \% \pm 17.0 \%, 134.9 \% \pm 22.3 \%$, and $111.6 \% \pm$ $26.2 \%$ at 1,2 , and 3 months, respectively) (Figure 4, E).

\section{Potential Association of Vascular Endothelial Growth Factor and Stromal Cell-Derived Factor 1 With the Positive Effects of ONO-1301 Elution}

The expressions of VEGF and SDF-1 in the neointimal tissue were analyzed to explore potentially associated factors with the histologic changes. The expressions of both VEGF and SDF-1 tended to be upregulated in the $\mathrm{ONO}(+)$ group compared with the $\mathrm{ONO}(-)$ group at 1 month and 3 months (not statistically significant) (Figure 5, A). In addition, the aortic wall of the stent graft implantation site at 2 months contained a number of CD31-positive endothelial cells, $\alpha$ SMA-positive smooth muscle cells, or myofibroblasts, and fibroblast specific antigen-1-positive fibroblasts that were also positive for prostacyclin (IP) receptor, to which ONO-1301 acts as a ligand (Figure 5, B). The ONO-1301 concentration-dependent VEGF and SDF-1 expression in the aortic endothelial cells, aortic smooth muscle cells, and aortic fibroblasts of human origin in vitro were assessed using enzyme-linked immunosorbent assay (Figure 5, C). VEGF and SDF-1 secretion from the aortic smooth muscle cells and fibroblasts increased significantly, with a positive correlation with ONO-1301 concentrations. In contrast, no increase in VEGF and SDF-1 secretion from the aortic endothelial cells was evident after the addition of ONO-1301.

\section{DISCUSSION}

This study demonstrated that the creation of an ONO1301-eluting stent graft and the fluoroscopy-guided implantation of this graft into the thoracic aorta of normal canines were feasible and safe, producing high ONO-1301 concentrations in the aortic tissue underlying the graft-implanted site for up to 3 months; further, the systemic blood plasma concentrations remained well below the safety levels. ${ }^{9}$ Implantation of the ONO-1301-eluting stent graft resulted in stronger, denser, and more fibrous adhesion between the aortic wall and the graft in addition to increased expression of factors associated with adhesion, blood vessel creation, and tissue healing, when compared with the stents without ONO-1301.

To the best of our knowledge, this is the first report of the effects of ONO-1301 elution on stent graft attachment to the aortic wall, although several attempts to enhance the biological prosthetic graft attachment to the aortic wall have been reported. Lerouge and colleagues ${ }^{15}$ reported the results of an in vitro study in which nitrogen-rich polymerized plasma promoted the cell ingrowth in polyester and polytetrafluoroethylene graft fabric. Charbonneau and colleagues ${ }^{16}$ reported an in vitro study wherein incorporation of chondroitin sulfate in the stent graft enhanced cell adhesion and viability. However, the in vivo feasibility or safety of these technologies remains unclear, whereas this study demonstrated the feasibility and safety of an ONO-1301-eluting stent graft using a clinically relevant implantation method in a large animal model. Although van der Bas and colleagues ${ }^{17}$ reported that coating stent grafts with basic fibroblast growth factorimpregnated collagen enhanced ingrowth into the fabric and neointimal formation in the aorta in a swine model, it may be reasonable to suggest that the ONO-1301-eluting stent graft is more advantageous in the clinical setting because it releases the drug over 3 months postimplantation, potentially contributing to an enhanced healing process between the stent graft and the aortic wall that would progress past the 3 months, as reported previously ${ }^{18}$ and confirmed in this study. However, the ONO-1301 dose, graft material, and creation protocol for the stent graft need to be optimized for clinical studies.

ONO-1301 produces various tissue healing effects on damaged tissues or organs where it is administered by acting on endothelial cells, vascular smooth muscle cells, and fibroblasts via binding with the IP receptor. ${ }^{11}$ In fact, the aorta contains cells that express the IP receptor and various factors associated with tissue healing, such as VEGF and SDF-1. VEGF has been reported to promote endothelial cell migration and angiogenesis, ${ }^{19,20}$ whereas SDF-1 induces the local homing of bone marrow cells through the SDF-1/CXCR4 axis, which promotes neointimal formation and neovasculogenesis. ${ }^{21,22}$ These factors were upregulated depending on ONO-1301 concentrations, indicating that the biological effects of ONO-1301 led to enhanced neointimal formation and fibrous tissue, filling the gap and strengthening the mechanical force of the attachment between the graft and the aortic wall. Moreover, through the prostaglandin I-IP system, endothelial progenitor cells have been reported to 
recruit to the injured vessels and participate in reendothelialization. ${ }^{23}$ One may assume that ONO-1301 would produce negative effects on tissue fibrosis via the upregulation of antifibrotic factors, such as hepatocyte growth factor, although this was not observed in the present study. However, antifibrotic effects by ONO-1301 have been reported in pathologies wherein the accumulation of fibrotic components exacerbates tissue or organ damage, such as that occurring in advanced cardiac failure and pulmonary fibrosis. ${ }^{7,8}$ It is possible that ONO-1301 acts in a regenerative manner, with effects that are antifibrotic or profibrotic depending on the existing pathology.

In this study, the ONO-1301-eluting stent was examined to extend the indication of endovascular treatment for complicated aortic morphologies or anatomies, such as short neck, severely angulated neck, or reverse taper, for which treatment using presently available stent grafts is not indicated. Adhesive properties of the stent graft are of great benefit in these cases in which only a short landing zone is available. As shown in this study, the ONO-1301eluting stent graft has greater adhesive properties than the standard stent graft, indicating the usefulness of this new stent graft for these pathologies. Considering that endoleaks are primarily due to arch curvature or folds that prevent contact between the graft and aortic wall, which was also observed in the present study, the adhesive properties of the method we present may be of limited benefits. However, our data showed that the space between the graft and the aortic wall could be filled with newly generated tissue, suggesting that the new device might prevent the fold-related type I endoleak.

\section{Study Limitations}

This study is limited by the use of a normal animal model rather than a pathologic model. The biological response toward ONO-1301-eluting stents in human atherosclerotic aortic aneurysms would differ from that observed in the current study. However, the human aortic aneurysm border zone, where the stent graft is deployed, is known to contain a greater number of activated inflammatory cells than the normal aortic wall. ${ }^{24,25}$ These cells may synergistically activate the adjacent cells in the aortic wall after ONO-1301 administration, contributing to enhanced biological stent graft attachment to the aorta. ${ }^{26}$ Further basic and preclinical studies are needed to clarify these issues.

In regard to the safety of prostacyclin against the atherosclerotic aortic aneurysm wall, prostacyclin is reportedly produced from the endothelial cells through the cyclooxygenase (COX)-1 axis in the presence of a stable condition and has a protective effect on the aortic wall. In the presence of vascular damage, COX-2 is induced and produces prostacyclin for vascular protection. However, with significant inflammation or disease, increased COX-2 expression produces a large amount of alternative prostanoids (eg, prostaglandin E2) that induce matrix metalloproteinases and cell death, resulting in tissue destruction and vascular lesion instability. ${ }^{27,28}$ King and colleagues $^{29}$ reported that these destructive effects are similar to those that occur in abdominal aortic aneurysms. On the other hand, hepatocyte growth factor, which is reportedly induced from ONO-1301-exposed fibroblasts or smooth muscle cells, ${ }^{9,11}$ could have anti-inflammatory effects in human abdominal aortic aneurysms. ${ }^{30}$ Therefore, prostacyclin has a theoretically protective effect on the aortic wall and should not be associated with aneurysm progression, and in the present study, atherosclerotic changes were not observed in this canine model. Moreover, no adverse effect was observed on aneurysmal formation or progression with the clinical use of iloprost (a synthetic prostacyclin analog) in the treatment of pulmonary hypertension. ${ }^{31,32}$ These findings support the safety of prostacyclin in the aortic aneurysm pathology; however, its safety should be verified using an atherosclerotic aneurysm animal model, which may prove difficult because of the lack of an available atherosclerotic large animal model.

\section{CONCLUSIONS}

ONO-1301 elution over the stent graft strengthened the mechanical and biological attachment of the stent graft to the native aortic wall via enhanced neointimal formation over the graft surface and enhanced migration of fibrous tissue components into the graft in a normal canine model. This new device may be useful in preventing stent graft-related complications associated with inadequate attachment between the graft and the aortic wall, although further studies are warranted.

The authors thank Yoshiki Sakai, Shigeru Matsumi, Toshika Senba, Akima Harada, Mayu Kataoka, and Hiromi Nishinaka for excellent technical assistance.

\section{References}

1. Greenhalgh RM, Brown LC, Kwong GP, Powell JT, Thompson SG; EVAR trial participants. Comparison of endovascular aneurysm repair with open repair in patients with abdominal aortic aneurysm (EVAR trial 1), 30-day operative mortality results: randomised controlled trial. Lancet. 2004; 364:843-8.

2. De Bruin JL, Baas AF, Buth J, Prinssen M, Verhoeven EL, Cuypers PW, et al. Long-term outcome of open or endovascular repair of abdominal aortic aneurysm. N Engl J Med. 2010;362:1881-9.

3. Lederle FA, Freischlag JA, Kyriakides TC, Matsumura JS, Padberg FT Jr, Kohler TR, et al. Long-term comparison of endovascular and open repair of abdominal aortic aneurysm. N Engl J Med. 2012;367:1988-97.

4. Malina M, Brunkwall J, Ivancev K, Jönsson J, Malina J, Lindblad B. Endovascular healing is inadequate for fixation of Dacron stent-grafts in human aortoiliac vessels. Eur J Vasc Endovasc Surg. 2000;19:5-11.

5. Hayashi K, Nagamatsu T, Oka T, Suzuki Y. Modulation of anti-glomerular basement membrane nephritis in rats by ONO-1301, a non-prostanoid prostaglandin I2 mimetic compound with inhibitory activity against thromboxane A2 synthase. Jpn J Pharmacol. 1997;73:73-82. 
6. Rudd JA, Qian Y, Tsui KK, Jones RL. Non-prostanoid prostacyclin mimetics as neuronal stimulants in the rat: comparison of vagus nerve and NANC innervation of the colon. Br J Pharmacol. 2000;129:782-90.

7. Murakami S, Nagaya N, Itoh T, Kataoka M, Iwase T, Horio T, et al. Prostacyclin agonist with thromboxane synthase inhibitory activity (ONO-1301) attenuates bleomycin-induced pulmonary fibrosis in mice. Am J Physiol Lung Cell Mol Physiol. 2006;290:L59-65.

8. Kubota Y, Miyagawa S, Fukushima S, Saito A, Watabe H, Daimon T, et al. Impact of cardiac support device combined with slow-release prostacyclin agonist in a canine ischemic cardiomyopathy model. J Thorac Cardiovasc Surg. 2014;147:1081-7.

9. Nakamura K, Sata M, Iwata H, Sakai Y, Hirata Y, Kugiyama K, et al. A synthetic small molecule, ONO-1301, enhances endogenous growth factor expression and augments angiogenesis in the ischaemic heart. Clin Sci (Lond). 2007;112: 607-16.

10. Imanishi Y, Miyagawa S, Fukushima S, Ishimaru K, Sougawa N, Saito A, et al. Sustained-release delivery of prostacyclin analogue enhances bone marrow-cell recruitment and yields functional benefits for acute myocardial infarction in mice. PLoS One. 2013;8:e69302.

11. Ishimaru K, Miyagawa S, Fukushima S, Saito A, Sakai Y, Ueno T, et al. Synthetic prostacyclin agonist, ONO1301, enhances endogenous myocardial repair in a hamster model of dilated cardiomyopathy: a promising regenerative therapy for the failing heart. J Thorac Cardiovasc Surg. 2013;146:1516-25.

12. Conners MS III, Sternbergh WC III, Carter G, Tonnessen BH, Yoselevitz M, Money SR. Endograft migration one to four years after endovascular abdominal aortic aneurysm repair with the AneuRx device: a cautionary note. $J$ Vasc Surg. 2002;36:476-84.

13. Mohan IV, Laheij RJ, Harris PL, EUROSTAR COLLABORATORS. Risk factors for endoleak and the evidence for stent-graft oversizing in patients undergoing endovascular aneurysm repair. Eur J Vasc Endovasc Surg. 2001;21:344-9.

14. Hazekawa M, Sakai Y, Yoshida M, Haraguchi T, Morisaki T, Uchida T. Preparation of ONO-1301-loaded poly(lactide-co-glycolide) microspheres and their effect on nerve conduction velocity. J Pharm Pharmacol. 2011;63:362-8.

15. Lerouge S, Major A, Girault-Lauriault PL, Raymond MA, Laplante P, Soulez G, et al. Nitrogen-rich coatings for promoting healing around stent-grafts after endovascular aneurysm repair. Biomaterials. 2007;28:1209-17.

16. Charbonneau C, Gautrot JE, Hébert MJ, Zhu XX, Lerouge S. Chondroitin-4sulfate: a bioactive macromolecule to foster vascular healing around stent-grafts after endovascular aneurysm repair. Macromol Biosci. 2007;7: 746-52.

17. van der Bas JM, Quax PH, van den Berg AC, Visser MJ, van der Linden E, van Bockel JH. Ingrowth of aorta wall into stent grafts impregnated with basic fibroblast growth factor: a porcine in vivo study of blood vessel prosthesis healing. J Vasc Surg. 2004;39:850-8.
18. Kato M, Matsuda T, Kaneko M, Ueda T, Kuratani T, Yoshioka Y, et al. Experimental assessment of newly devised transcatheter stent-graft for aortic dissection. Ann Thorac Surg. 1995;59:908-15.

19. Pola R, Gaetani E, Flex A, Aprahamian TR, Bosch-Marcé M, Losordo DW, et al. Comparative analysis of the in vivo angiogenic properties of stable prostacyclin analogs: a possible role for peroxisome proliferator-activated receptors. $J \mathrm{Mol}$ Cell Cardiol. 2004;36:363-70.

20. Hoeben A, Landuyt B, Highley MS, Wildiers H, Van Oosterom AT, De Bruijn EA. Vascular endothelial growth factor and angiogenesis. Pharmacol Rev. 2004;56:549-80.

21. Zernecke A, Schober A, Bot I, von Hundelshausen P, Liehn EA, Möpps B, et al. SDF-1alpha/CXCR4 axis is instrumental in neointimal hyperplasia and recruitment of smooth muscle progenitor cells. Circ Res. 2005;96:784-91.

22. Yamaguchi J, Kasuno KF, Masuo O, Kawamoto A, Silver M, Murasawa S, et al. Stromal cell-derived factor-1 effects on ex vivo expanded endothelial progenitor cell recruitment for ischemic neovascularization. Circulation. 2003;107:1322-8.

23. Kawabe J, Yuhki K, Okada M, Kanno T, Yamauchi A, Tashiro N, et al. Prostaglandin I2 promotes recruitment of endothelial progenitor cells and limits vascular remodeling. Arterioscler Thromb Vasc Biol. 2010;30:464-70.

24. Cohen JR, Keegan L, Sarfati I, Danna D, Mlardi C, Wise L. Neutrophil chemotaxis and neutrophil elastase in the aortic wall in patients with abdominal aortic aneurysms. J Invest Surg. 1991;4:423-30.

25. Freestone T, Turner RJ, Coady A, Higman DJ, Greenhalgh RM, Powell JT. Inflammation and matrix metalloproteinases in the enlarging abdominal aortic aneurysm. Arterioscler Thromb Vasc Biol. 1995;15:1145-51.

26. Massberg S, Vogt F, Dickfeld T, Brand K, Page S, Gawaz M. Activated platelets trigger an inflammatory response and enhance migration of aortic smooth muscle cells. Thromb Res. 2003;110:187-94.

27. Bishop-Bailey D, Mitchell JA, Warner TD. COX-2 in cardiovascular disease. Arterioscler Thromb Vasc Biol. 2006;26:956-8.

28. Eldor A, Falcone DJ, Hajjar DP, Minick CR, Weksler BB. Recovery of prostacyclin production by de-endothelialized rabbit aorta. Critical role of neointimal smooth muscle cells. J Clin Invest. 1981;67:735-41.

29. King VL, Trivedi DB, Gitlin JM, Loftin CD. Selective cyclo-oxygenase-2 inhibition with celecoxib decreases angiotensin II-induced abdominal aortic aneurysm formation in mice. Arterioscler Thromb Vasc Biol. 2006;26:1137-43.

30. Shintani Y, Aoki H, Nishihara M, Ohno S, Furusho A, Hiromatsu S, et al. Hepatocyte growth factor promotes an anti-inflammatory cytokine profile in human abdominal aortic aneurysm tissue. Atherosclerosis. 2011;216:307-12.

31. Sawheny E, Ellis AL, Kinasewitz GT. Iloprost improves gas exchange in patients with pulmonary hypertension and ARDS. Chest. 2013;144:55-62.

32. Olschewski H, Simonneau G, Galiè N, Higenbottam T, Naeije R, Rubin LJ, et al. Inhaled iloprost for severe pulmonary hypertension. N Engl J Med. 2002;347: $322-9$. 

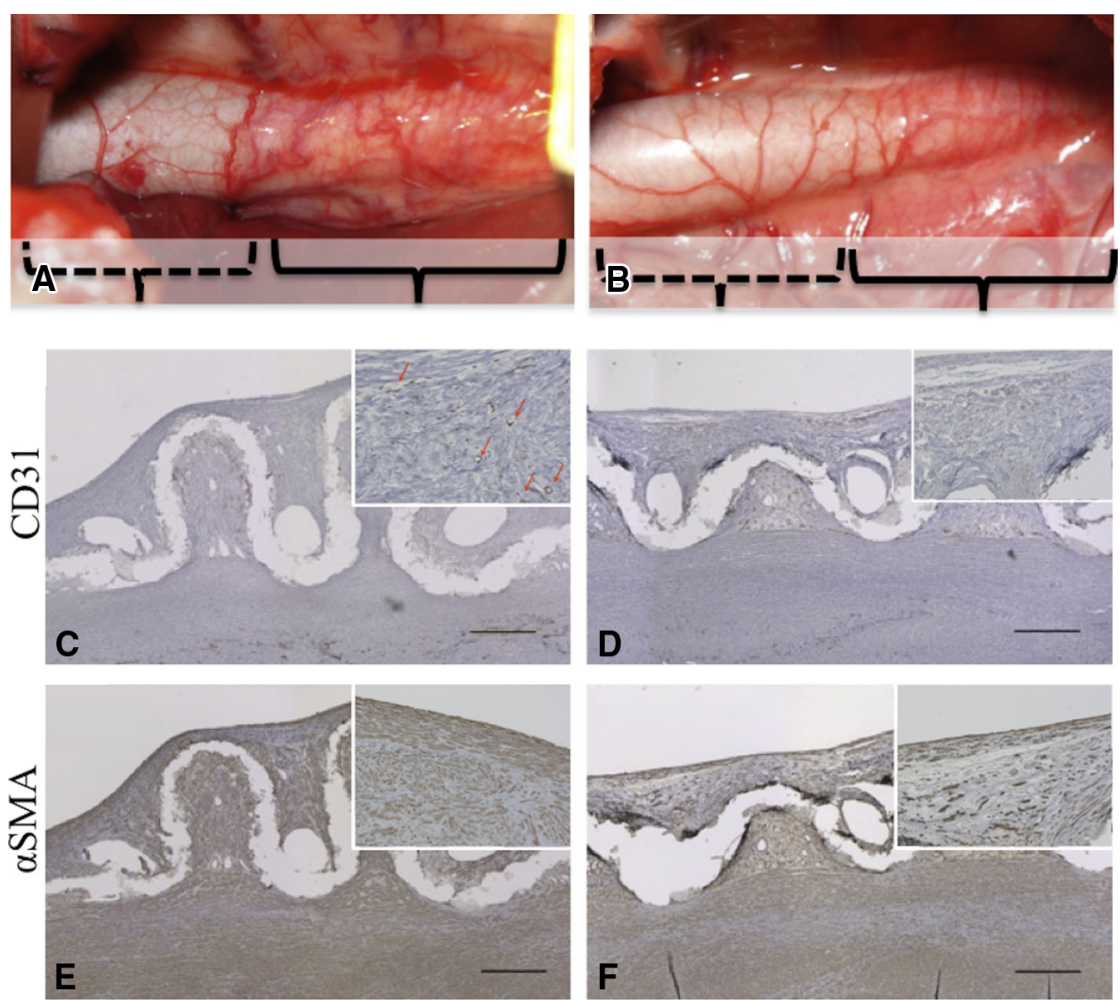

FIGURE E1. A and B, Adventitia of the aorta at 2 months in the $\mathrm{ONO}(+)$ group (A) and $\mathrm{ONO}(-)$ group. B, Solid line: stent graft implantation area, dotted line: nonimplantation area. C-F, CD31-positive capillary networks increased, and $\alpha$ SMA-positive components were denser in the neointimal tissues in the $\mathrm{ONO}(+)$ group than in the $\mathrm{ONO}(-)$ group $(\mathrm{C}$ and $\mathrm{E}, \mathrm{ONO}(+)$; D and $\mathrm{F}$ : $\mathrm{ONO}(-)$ at 2 months). Scale bar $=500 \mu \mathrm{m}$. SMA, Smooth muscle actin; $C D$, cluster of differentiation. 